\title{
PSA flare after initiation of abiraterone acetate
}

\author{
Shravan K Narmala, MD, and Brian C Boulmay, MD
}

Section of Hematology/Oncology, Department of Medicine, Louisiana State University Health Sciences Center, New Orleans

$\mathrm{P}$ rostate cancer is the second-most common cause of male cancer-related death among US men. The American Cancer Society estimates that in 2014 there will be about 233,000 new cases of prostate cancer and about 29,500 deaths due to prostate cancer. ${ }^{1}$ Sixty percent of cases are diagnosed in men aged 65 years or older. Localized prostate cancers are managed with active surveillance or external beam radiation therapy or radical prostatectomy after risk stratification. Advanced prostate cancers are managed with hormonal therapy for castrate sensitive prostate cancer and with novel androgen blocking therapies, chemotherapy, or radio-immunotherapy for castrate resistant prostate cancers. Prostate-specific antigen (PSA) flare is characterized by a rise in the PSA level, followed by a decline to below baseline values after starting therapies such as androgen deprivation therapy, systemic chemotherapy, or local therapies such as brachytherapy or cryotherapy.

\section{Case presentation}

A 72-year-old man was diagnosed in 1995 with a locally advanced prostate cancer with a Gleason score of 3+3 (range, 2-10; low score: tumor less likely to spread, high score: tumor more likely to spread) and a prostate-specific antigen (PSA) of $16 \mathrm{ng} / \mathrm{mL}$ (range for normallevelsfor men aged 70-79, 0-6.5 $\mathrm{ng} / \mathrm{mL}$ ). He was treated with external beam radiation therapy. Follow-up annual PSA testing showed a PSA nadir of $2.0 \mathrm{ng} / \mathrm{mL}$.

In January 2009, the patient's PSA level rose to $2.9 \mathrm{ng} / \mathrm{mL}$. An evaluation with a spinal magnetic resonance imaging and bone scan showed metastases in 2 lumbar vertebral bodies. The patient was started on bicalutamide $50 \mathrm{mg}$ orally daily and on leuprolide $45 \mathrm{mg}$ sub-cutaneous injections every 6 months. The PSA nadir was less than $0.01 \mathrm{ng} / \mathrm{mL}$. After 12 months, his PSA level rose to $14.0 \mathrm{ng} / \mathrm{mL}$. Docetaxel $75 \mathrm{mg} / \mathrm{m}^{2}$ every 6 months was initiated, with a PSA decline to $6.2 \mathrm{ng} / \mathrm{mL}$ after 3 cycles of therapy. Further chemotherapy was held secondary to patient intolerance. A reevaluation of the patient 3 months later showed a PSA level of $36.3 \mathrm{ng} / \mathrm{ml}$. Abiraterone acetate (AA) $1,000 \mathrm{mg}$ orally once daily and prednisone $5 \mathrm{mg}$ orally twice daily were then initiated; 6 weeks later, his PSA level rose to $89.3 \mathrm{ng} / \mathrm{ml}$. Clinically, the patient described subtle increase in lower back pain consistent with progression at a known lumbar vertebrae metastatic site. However, additional bone scans were not performed. $\mathrm{AA}$ and prednisone were then discontinued. After 1 month, the PSA level had declined to $21.7 \mathrm{ng} / \mathrm{mL}$ without any new therapeutic intervention, and the patient had improved low back pain. After an additional 10 weeks, his PSA level declined further to $4.2 \mathrm{ng} / \mathrm{mL}$. AA $1,000 \mathrm{mg}$ orally once daily was reinitiated and there was no further rise in the patient's PSA level.

\section{Discussion}

Upregulation of androgen biosynthesis enzymes is a unique molecular alteration that has been described in castrate resistant prostate cancer (CRPC) and leads to an increase in intratumoral androgen concentration. AA, a selective androgen biosynthesis inhibitor of CYP17, has been shown to inhibit this mechanism, thereby suppressing an important stimulus of CRPC growth. In phase 3 trials, AA with prednisone was shown to prolong overall survival in patients with both chemotherapy-naive and docetaxel-refractory metastatic CRPC. ${ }^{2}$

PSA flare is characterized by a rise in the PSA level shortly after starting therapy therapies such as androgen deprivation therapy, systemic chemotherapy or local therapies such as brachytherapy or cryotherapy, followed by a decline to below baseline values, as defined by PSA level values recorded before starting therapy for prostate cancer. It is a known phenomenon with chemotherapy in CRPC. ${ }^{3}$ It used

Accepted for publication October 14, 2013. Correspondence: Shravan K Narmala, MD; snarma@lsuhsc.edu. Disclosures: The authors have no disclosures. JCSO 2014;12:191-192. (2014 Frontline Medical Communications. DOI 10.12788/ jeso.0045. 
to be that a rise in the PSA level was thought to indicate disease progression with chemotherapy, but recent studies have suggested that patients who have a PSA flare are true responders to chemotherapy. ${ }^{4,5}$ Although there have been reports of bone scan flare after the initiation of AA, there have not been any reports of PSA flare in patients who were treated with $A A .{ }^{6}$ In the present case, we elected to withhold further AA because AA-related PSA flare has not yet been described in the medical literature.

PSA elevation in our patient after the initiation of AA is suggestive of a flare phenomenon because the PSA level did not rise on rechallenge with the drug. A rise in the PSA level after the initiation of AA and its decline after AA withdrawal have recently been described, similar to the case we report. ${ }^{7}$ Our case emphasizes the usefulness of the Prostate Cancer Working Group 2 criteria, which recommend continuing treatment with newly initiated prostate cancer therapies for at least 12 weeks without clinical evidence for disease progression. ${ }^{8}$ We suggest that AA not be discontinued early in its treatment course if an asymptomatic PSA rise occurs.

\section{References}

1. American Cancer Society. What are the key statistics about prostate cancer? http://www.cancer.org/cancer/prostatecancer/detailedguide/ prostate-cancer-key-statistics. Revised March 12, 2014. Accessed April 16, 2014.
2. Ryan CJ, Smith MR, De Bono JS, et al. Interim analysis (IA) results of COU-AA-302, a randomized, phase III study of abiraterone acetate (AA) in chemotherapy-naive patients (pts) with metastatic castration-resistant prostate cancer (mCRPC) [ASCO LBA 4518]. J Clin Oncol. 2012;30(suppl).

3. Nelius T, Filleur S. PSA surge/flare-up in patients with castrationrefractory prostate cancer during the initial phase of chemotherapy. Prostate. 2009;69:1802-1807.

4. Nelius T, Klatte T, de Riese W, Filleur S. Impact of PSA flare-up in patients with hormone-refractory prostate cancer undergoing chemotherapy. Int Urol Nephrol. 2008;40:97-104.

5. Olbert PJ, Hegele A, Kraeuter P, Heidenreich A, Hofmann R, Schrader AJ. Clinical significance of a prostate-specific antigen flare phenomenon in patients with hormone-refractory prostate cancer receiving docetaxel. Anticancer Drugs. 2006;17:993-996.

6. Ryan CJ, Shah S, Efstathiou E, et al. Phase II study of abiraterone acetate in chemotherapy-naive metastatic castration-resistant prostate cancer displaying bone flare discordant with serologic response. Clin Cancer Res. 2011;17:4854-4861.

7. Gauthier H, Bousquet $\mathrm{G}$, Poussel D, et al. Abiraterone acetate withdrawal syndrome: does it exist? Case Rep Oncol. 2012;5:385-387.

8. Scher HI, Halabi S, Tannock I, et al. Design and end points of clinical trials for patients with progressive prostate cancer and castrate levels of testosterone: Recommendations of the prostate cancer clinical trials working group. J Clin Oncol. 2008;26:1148-1159. 